\title{
The Impact of Logistics Industry on China's Regional Economic Growth Based on Theil Index Analysis
}

\author{
Liangliang CHEN \\ School of Economics and Management \\ Beijing Institute of Graphic Communication \\ Beijing, China \\ chenliangliang@bigc.edu.cn
}

\author{
Zhihong TIAN \\ School of Economics and Management \\ Beijing Institute of Graphic Communication \\ Beijing, China \\ tianzhihong@bigc.edu.cn
}

\begin{abstract}
This paper aims to investigate the impact of logistics industry on China's regional economic growth. In particular, the input-output relationships in the regions are analyzed based on the biodegradable nature of Theil index method. We find that there is a relatively small interaction effect between logistics industry and economic growth in three regions of China-the southern coast, the southwest and the northwest regions while there is a significant effect between logistics industry and economic growth in other regions. The results imply the limitation of the growth of logistics industry promoting the region development. This research contributes to further challenging by China in achieving a regionally balanced growth. It argues that the differences should not be ignored and gives suggestions on how to reduce the economic disparities.
\end{abstract}

Keywords-Logistics industry; Regional Logistics; Regional economies; Regional disparities

\section{INTRODUCTION}

During the period of reform and structural change, China's economy has been continuously developing at a remarkable rate. However, there are debates that income inequality among regions and sectors has been widening. On this issue, author examined regional growth convergence since 1990 considering the sector-wise provincial growth accounting. One of the findings shown was that capital accumulation per labor in the tertiary industry sector was a factor for regional growth divergence in China.

Similarly, in the tertiary industry sector, structural changes differed among regions. Figure 1 shows the share of the logistics service industry in the value added to the tertiary sector in eight Chinese regions since 2008. The dataset covers as following here in China: Northeast: Liaoning, Jilin, Heilongjiang. Northern Coast: Beijing, Tianjin, Hebei, Shandong. East Coast: Shanghai, Jiangsu, Zhejiang. South coast: Fujiang, Guangdong, Hainan. Middle reach of the Huanghe River: Shaanxi, Shanxi, Henan, Nei Monggol. Middle reach of the Yangtze: Hubei, Hunan, Jiangxi, Anhui. Southwest Yunnan, Tibet, Guizhou, Sichuan, Chongqing, Guangxi. Northwest: Gansu, Qinghai, Ningxia, Xinjiang.

As this figure describes, the Logistics industry increases its weight in the tertiary sector in most regions, except in the Northeast region. The increase in the share of the logistics industry in the value added to the industry sector is remarkable

Project supported by the National Social Science Foundation of China (Grant No 15CJY003), and BIGC No.041901180021078,

No.20190116001/007, No.04190117001/030/003. especially in the Southwest, South Coast, East Coast, and in the middle reach of the Huanghe River.

From the author's findings mentioned above, this paper analyzes the regional distribution of investment in the logistics and non- logistics industries during 2008-2016. As capital stock estimation in the sub- tertiary is constrained by the unavailability of data in China, focusing on investment will provide us with a limited but substitutable view on the roles of resource allocation within these sectors in regional development.

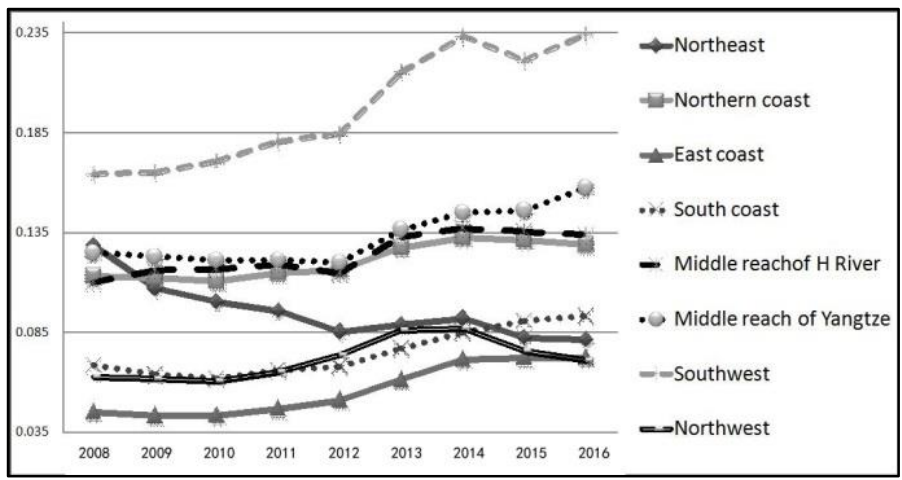

Fig. 1 Share of the Logistics industry in the value added in the tertiary sector in 8 regions

Source: China Industry Economic Statistical Yearbook and China Industry Economic Yearbook which published by China Statistics Press.

In order to identify investment distribution, measurement is introduced. The Theil index is adopted in this study. This is a famous index for describing disparity; its decomposition property into sub-groups is useful for the present study.

We are also interested in the effects of logistics industry growth on the tertiary industry. Specifically, the author is interested to know whether these effects have a significant role in the regional economy. It would contribute to further challenging by China in achieving a regionally balanced growth. This paper will discuss the limitations of such effects; the discussion will be based on the input-output relationship between the tertiary industry sector and the logistics service industry in the regions.

The remainder of this paper will be as follows: part 2 describes the details of the Theil index, which we adopt as 
disparity measurements; part 3 describes the data used for estimation; part 4 shows the estimation results; and, part 5 is a discussion on our findings on the linkage effect in the inputoutput relationship.

\section{Details OF THE THEIL INDEX}

For the purposes mentioned above, the question on how investment has been allocated in the logistics and the nonlogistics industries and among regions is of interest to us. In this context, it is desirable that our measure of disparity provides information on investment distribution for a regional comparison between the logistics and the non-logistics industries, or for a comparison of the logistics and the nonlogistics industries among regions.

We adopted the Theil index for a measurement of the disparities on investment and value added per labor within the Chinese tertiary industry. The Theil index is one of the most often used disparity measurements. This index is often used for describing income equality among individuals. However, it is also often utilized to identify regional disparity in a country. In previous studies, it was used within the context of the Chinese economy.

For our present purpose, the Theil index is used to identify regional disparities on value added per labor and investment per labor. That is, this paper estimates the distribution of labor productivity and the investment labor ratio between the subsectors in the tertiary industry, namely, the logistics sector and the non-logistics sector. However, the validity of the adoption of this index in this study is in an important property of this index. This index can be decomposed into the sum of disparity measures of within- and between-subgroups. This is an advantage for us, specifically on the distribution of investment in the logistics sector within regions, in comparison with the non-logistics industry.

In order to identify this decomposition property, the definition, according to the Theil index, of the valued added per labor for the Chinese tertiary industry sector and its decomposition, are as follows:

$$
\begin{aligned}
& T^{V}=\sum_{i} \sum_{j}\left(\frac{Y_{i j}}{Y}\right) \log \left(\frac{Y_{i j} / Y}{L_{i j} / L}\right)=T_{W}^{V}+T_{B}^{V} \\
& T_{W}^{V}=\sum_{i}\left(\frac{Y_{i}}{Y}\right) \cdot T_{p i}^{V}, T_{p i}^{V}=\sum_{j}\left(\frac{Y_{i j}}{Y_{i}}\right) \log \left(\frac{Y_{i j} / Y_{i}}{L_{i j} / L_{i}}\right) \\
& T_{B}^{V}=\sum_{i}\left(\frac{Y_{i}}{Y}\right) \log \left(\frac{Y_{i} / Y}{L_{i} / L}\right)
\end{aligned}
$$

Where $T^{V}$ is the Theil index for value added per labor, which describes overall inequality; $Y$ is value added in the Chinese tertiary industry; $Y_{i j}$ is value added in the sub-tertiary industry sector $j$ (logistics/non-logistics) in region $i ; L$ is labor in the tertiary industry of the country; $L_{i j}$ is labor in region $i$ and sub-tertiary industry sector $j$. It is known that the Theil index $\left(T^{V}\right)$ can be decomposed into two terms: a between-group component $T_{B}^{V}$ and a within-group component $T_{W}^{V}$. In the definition above, 'group' is consistent with 'region', that is, $T_{B}^{V}$ denotes a between regions component, and $T_{W}^{V}$ can be interpreted as a within a region component. As the definition states, a within region component is defined as the weighted sum of the sub-industries' Theil index in region $i$ $\left(T_{p i}^{V}\right)$ by the share of industry's value added of region $i$ in value added of whole tertiary industry in China. By this decomposition, we can examine how the disparity between sub-industries in each region contributes to overall disparity.

As with the above definition, when $I$ denotes investment in the tertiary industry sector in China, and $I_{i j}$ denotes investment in sub-industry sector $j$ in region $i$, the Theil index of investment per labor for Chinese tertiary industry sector $T^{I}$, and its decomposition, is defined by substituting $I_{i j}$ for $Y_{i j}$ in Eqs. (1)-(3). This overall inequality in investment per labor can be decomposed into a between-group component $T_{B}^{I}$ and a within-group component $T_{W}^{I}$.

The above decompositions of the Theil index into within and between components are in terms of region. From the definitions, it is clear that this decomposition can be done in terms of sector. Hence, this study adopts this decomposition property of the Theil index in the following two ways.

$$
\begin{aligned}
& T=T_{\text {within_region }}+T_{\text {between_region }} \\
& T=T_{\text {within_sector }}+T_{\text {between_sector }}
\end{aligned}
$$

Where, $T$ denotes the Theil index for the overall inequality of the value added or investment per labor in the Chinese tertiary industry. As mentioned above, $T_{\text {within_region }}\left(T_{\text {within_sector }}\right)$ describes the weighted sum of the Theil index in each region (sector). This reflects disparities between sectors (regions) in each region (sector). That is, in Eq. (4), $T_{\text {within_region }}$ can be understood as the weighted sum of the regions' disparities between the logistics and the non-logistics industries. With this, the difference between the logistics and the non-logistics industries in each region, and how this difference contributes to overall country disparity, can be analyzed. In Eq. (5), $T_{\text {within_sector }}$ can be understood as the sectors' weighted sum of disparity between regions. In this equation, the question on how the disparity between regions in the logistics (nonlogistics) sector contributes to overall disparity can be analyzed. $T_{\text {between_region }}\left(T_{\text {between_sector }}\right.$ ) reveals the disparity in the whole tertiary industry between regions (sectors).

\section{DATA USED FOR ESTIMATION}

This chapter uses the panel data of 31 provinces and cities during 2007-2016 for the industry sectors in China. The details for each data item are described below.

\section{Source:}

Value added, labor, and fixed asset cost at the end of the period for various industries are available from each year's China Industry Economic Statistical Yearbook and China Industry Economic Yearbook which published by China Statistics Press and China Logistics Yearbook which published by China Federation of Logistics \& Purchasing (CFLP). From this source, capital formation (investment) is derived from the 
fixed assets-cost differences in between years. In this study, the current value series are used for deriving disparity measures for each year.

\section{Sectors:}

The China Logistics Yearbook which published by China Federation of Logistics \& Purchasing (CFLP). This study categorizes these sectors into two: a) the logistics sector contains communication and transportation, storage and transportation transport industry and delivery; b) the nonlogistics sector contains the others in tertiary industry sector in China Industry Economic Statistical Yearbook.

\section{Regions:}

This study categorizes all provinces and cities into eight regions: Northeast, Northern Coast, East Coast, South Coast, middle reach of the Huanghe River, middle reach of the Yangtze, Southwest, and Northwest China.

\section{ESTIMATION RESULTS}

\section{A. Within and Between Regions Decomposition}

The estimation results, including within and between regions decomposition, are shown in Figure 2 and Figure 3.

Figure 2 and Figure 3 helps us to understand the trends and the disparity changes in value added per labor and investment per labor, and to compare both in terms of between region effect and within region effect.

It must be noted that disparities of both investment and value added per labor in the Chinese tertiary industry in the late 2008s were larger than those in the early 2008s. Specifically, the disparities in investment per labor have been increasing since 2013

The between regions components are dominant in both disparities, and the size of between regions components are almost comparable to the disparities in investment and value added per labor, although the former has some fluctuations in the early 2008s. However, the within regions components for investment per labor are greater than for the value added per labor during the estimated period.

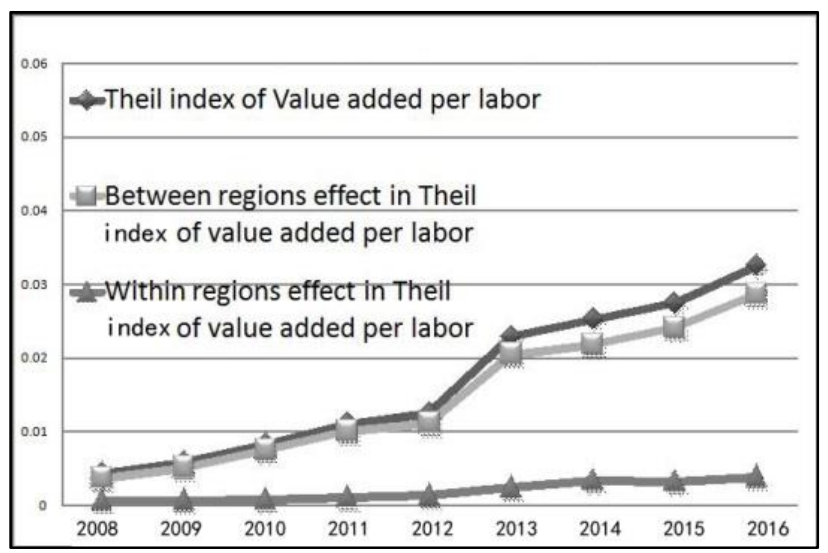

Fig. 2 Theil index of value added per labor (within and between regions)

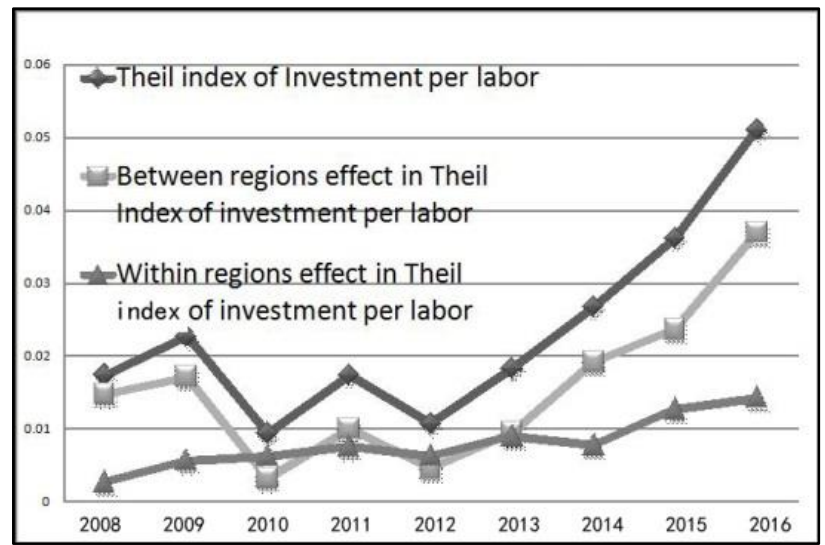

Fig. 3 Theil index of investment per labor (within and between regions)

Source: Author's estimation

For the within region component in the Theil index of investment per labor, it is useful to confirm its regional decomposition in order to identify the investment disparity between logistics and non-logistics sectors in each region. Figure 4 shows the decomposition into three larger regional categories, that is, east (Northern Coast, East Coast and South Coast), middle (northeast and middle reach of Yangtze) and west (middle reach of the Huanghe River, Southwest, and Northwest). This implies that increased investment per labor in the non-logistics industry, compared to that in the logistics industry in eastern regions, is not a negligible factor of increase and fluctuation in investment disparity. In addition, the disparity on investment per labor between the non-logistics and the logistics industries in the middle regions is also significant in 2013, 2015, and 2016.

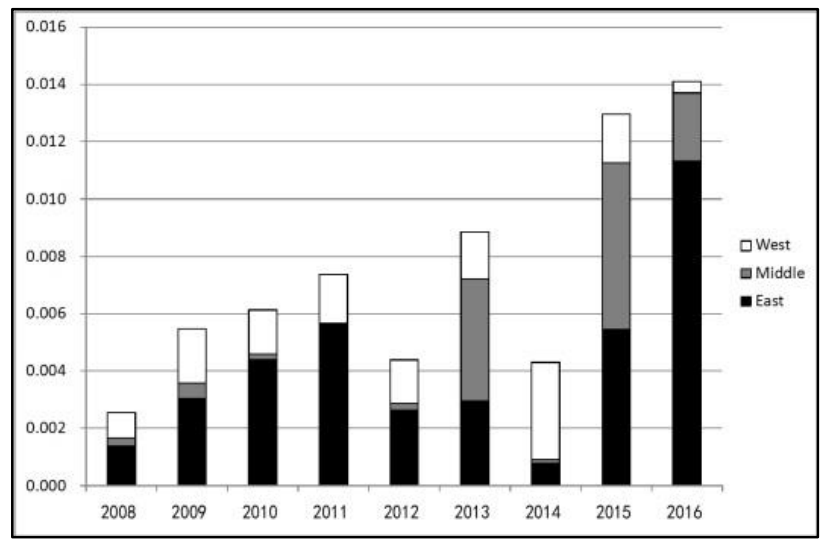

Fig. 4 Regional decomposition in within region component of Theil index for investment per labor

\section{B. Within and Between Sectors Decomposition}

As with the within and the between region estimations, we decomposed the Theil index into the terms of between and within sectors. Unfortunately, the estimated result cannot be shown here due to space restrictions. Because of this, we will only discuss the within logistics-sector component. This logistics sector's contribution to the within sector component 
describes the regional distribution of investment per labor in the logistics sector.

The within sector components include the regional disparity effects within the logistics and the non-logistics sectors. Therefore, among these terms, we shall confirm the regional distribution of both investment and valued added per labor in the logistics sector, as shown in Figure 5 and Figure 6. When labor productivity or investment per labor in a region is more than that of the average among regions, the figures take positive values. The within sector components of the Theil index are comparable with the value added and investment per labor, although the investment per labor had some fluctuations before 2013.

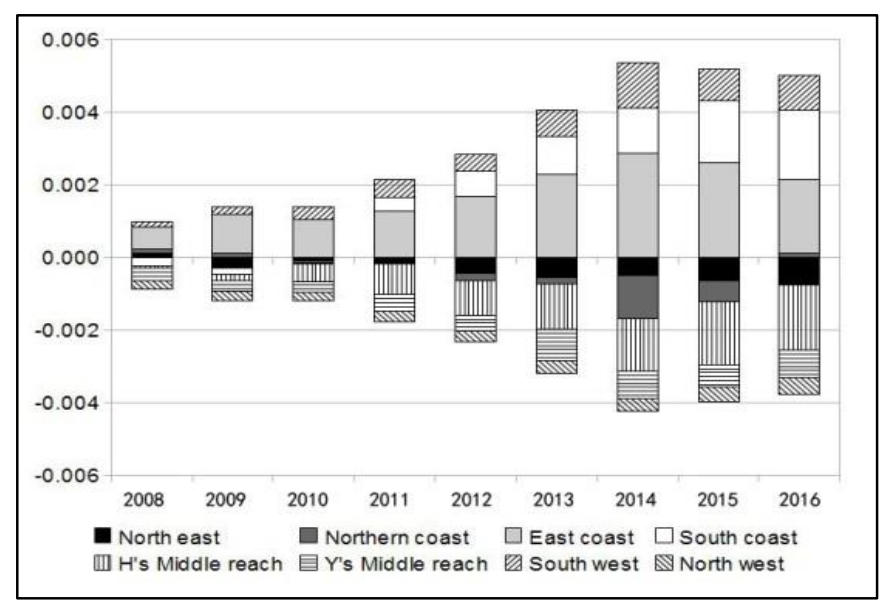

Fig. 5 Regional decomposition of logistics sector's contribution to within sector components of Theil index (Value added per labor)

Source: Author's estimation.

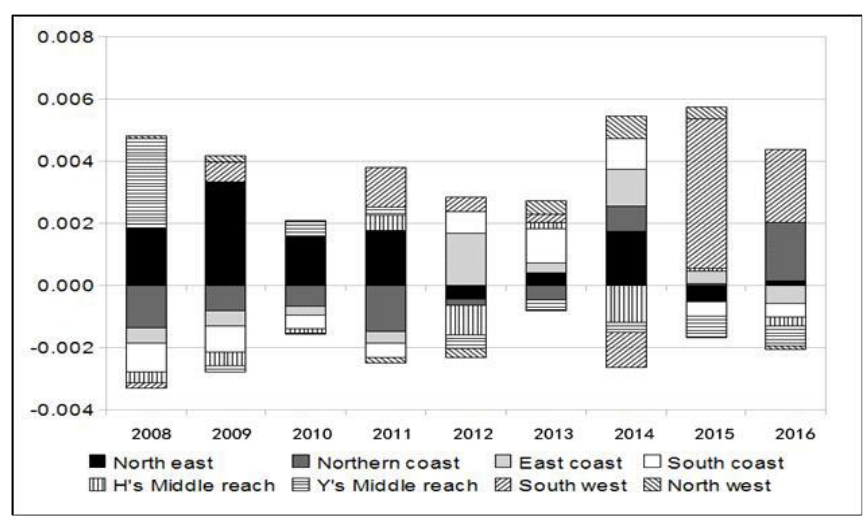

Fig. 6 Regional decomposition of logistics sector's contribution to within sector components of Theil index (Investment per labor)
The figure 5 shows positive values in the East Coast, South Coast, and in the Southwest. This implies higher labor productivity of the logistics sector in those regions. In the case of investment per labor as shown on the Figure 6, the figures fluctuate. We shall confirm these values on the left in Figure 6 by regions. First, the figure referring to Northeast, where the share of the logistics industry in the tertiary industry's value added has been decreasing since 2008, is confirmed. From 2008 to 2011, Northeast was a region where the investmentlabor ratio in the logistics sector was greater than the average among eight regions. From 2008 to 2011, however, this region decreased this value in the late of the estimation periods, but 2014.

The index of the investment per labor within the middle reach of the Yangtze region also shows positive values in 2008, 2010, and 2011. The Northern Coast shows negative values during most of the period concerned, but positive in the recent two years, that is, in 2014 and 2016.

As confirmed in Figure 1.1, the South Coast, the East Coast, and the Southwest are regions that show remarkable change in terms of the share of the logistics industry in the value added of the tertiary industry sector. Before 2012, the East Coast and the South Coast had less investment-labor ratio in the logistics industry than the average; these figures changed into positive in the mid-2008s. Interestingly, both regions show a parallel movement of increase in the value added shares of the logistics industry after 2012, as in Figure .1. In addition, the investment in the logistics sector in the Southwest is more than the average among the regions during 2011-2013 and 2015-2016.

The investment-labor ratio in the Northwest region was more than the average in 2013-2015. It must also be noted that the value added share of the logistics industry in this region peaked in 2013 and 2014, as identified in Figure 1.

\section{SUMMARY}

As described above, we considered the possibility of growth in the logistics sector in the South Coast and in the Southwest. We also looked at the role of the logistics sector in the Northwest region in regional disparity. However, in this aspect, we should be concerned with the linkage effect of this sector in these regions. Figure 7 shows the index of power of dispersion by the logistics sector in the Chinese regions, estimated from the inverse matrix of the inter-regional 17sector input-output table for the year 2008. This figure shows the index by summarizing it into some sectors decomposed into regions. 


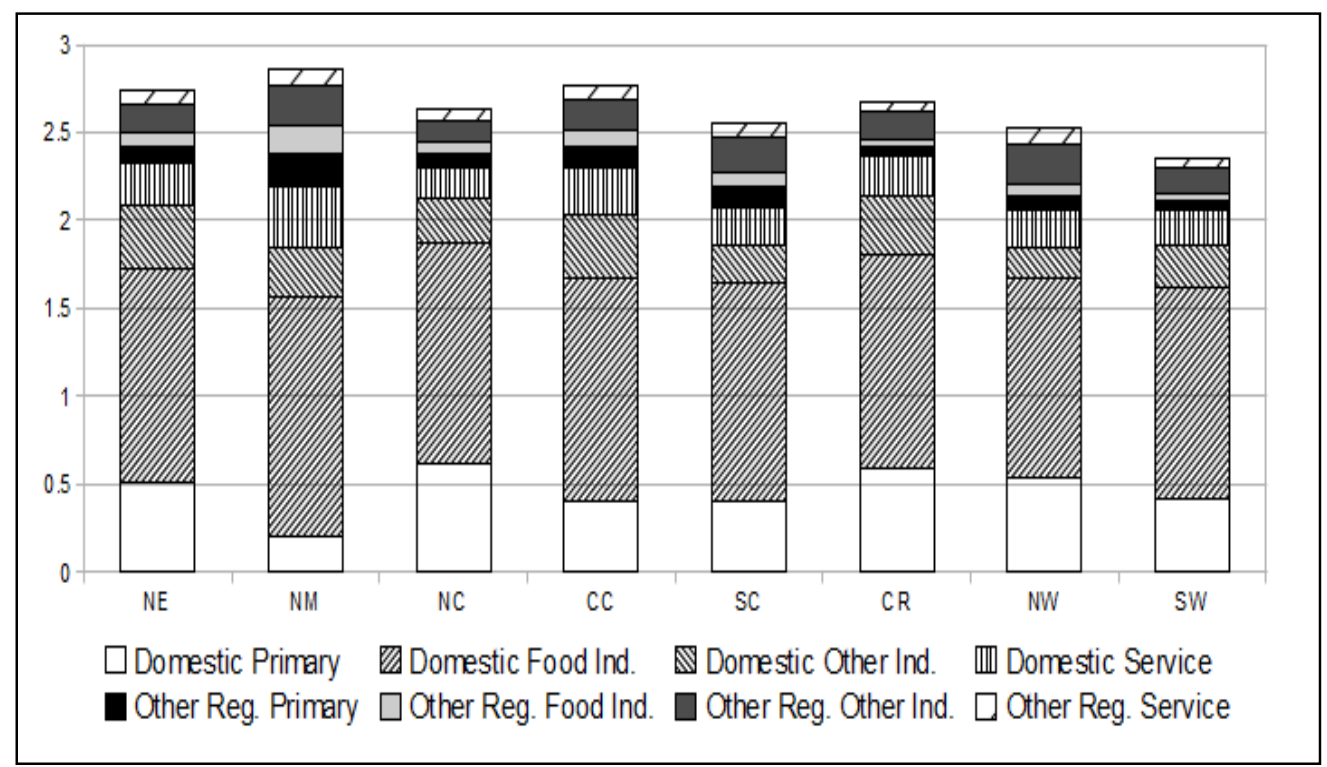

Fig. 7 Index of power of dispersion by the logistics sector Source: Author's categorization.
Note: NE, NM, NC, CC, SC, CR, NW, and SW denote North East, North Municipalities, North Coast, Central Coast, South Coast, Central Region, North West and South West.

In addition, because of the agricultural product logistics plays a very important position in the whole society, which is not only a matter of national economic operation efficiency and quality, but also closely related to the vital interests of farmers. With the development of industrialization of our country agriculture, agricultural products logistics industry gradually rise.

The primary sector includes agriculture and mining, but the former is a dominant in this figure. From the comparison in the effects of dispersion by a one-unit increase in the final demand of the logistics processing industry in each region, a relatively small linkage effect in the domestic agriculture in the South Coast, Southwest, and Northwest can be identified. This linkage effect seems to be correlated with the fact that the Northwest region depends more on the inflow of agriculture products from the other regions. These findings may imply the limitations of the effect of logistics sector growth in balancing regional development. This means that further effort to improve both the productivity in the agricultural sector and the efficiency of the logistics system in these regions is required.

\section{REFERENCES}

[1] Jinlong Wang, Shunyao Wu, Yang Jiao, Huy Quan Vu, "Study on Student Score Based on Data Mining", JCIT: Journal of Convergence Information Technology, Vol. 5, No. 6, pp. $171 \sim 179,2010$

[2] Xin-hua Zhu, Qing-ling Zeng, Qing-hua Cao, "A Complex XML Schema to Map the XML Documents of Distance Education Technical Specifications into Relational Database", JDCTA: International Journal of Digital Content Technology and its Applications, Vol. 4, No. 8, pp. $182 \sim 192,2010$.

[3] DAYAL- GULATI A and HUSAIN A.M. "Centripetal forces in China's economic take off”, IMF Working, 2000: 86.

[4] LI SHANTONG, FENG JIE, HOU YONGZHI, “ Ten Major Trends for Regional Development in China", China Development Review , 2004, $2(1): 6$.

[5] WANG X and FAN G. "Analysis on the Regional Disparity in China and the Influential Factors", Economic Research, 2004, 1(21): 50.

[6] KANBUR R. and ZHANG X, " Fifty Years of Regional education inequality in China: a Journey Through Central Planning, Reform, and Openness", Review of Development Economics, 2005, 1(9):35.

[7] YAO S and ZHANG Z, "On Regional education inequality and Diverging Clubs: A Case Study of Contemporary China", Journal of Comparative Economics, 2001, 29(3), pp.466-484.

[8] Lerong Yu, Renfu Luo, Linxiu Zhang, "Decomposing Income Inequality and Policy Implications in Rural China", China \& World Economy Volume 15, Issue 2, 2007.3, pages 44-58.

[9] CHEN Liangliang and SHUTO Hisato, "Structural Change and Regional Growth Convergence in China," Journal Of Rural Economics, Special Issue, 2010, pp.541-548. 